\title{
DÜBLIN
}

Technological University Dublin

ARROW@TU Dublin

\section{Multiphase CFD modelling and PIV validation of a UASB reactor}

\author{
Camila D' Bastiani \\ Technological University Dublin, camila.dbastiani@tudublin.ie \\ Jéferson Luis Alba \\ Universidade de Caxias do Sul \\ Gabriel Tomazzoni Mazzarotto \\ Universidade de Caxias do Sul
}

See next page for additional authors

Follow this and additional works at: https://arrow.tudublin.ie/engschmeccon

Part of the Biomechanical Engineering Commons

\section{Recommended Citation \\ Camila D’Bastiani, Jéferson Luis Alba, Gabriel Tomazzoni Mazzarotto, Severino Rodrigues de Farias Neto, Lademir Luiz Beal, Anthony Reynolds, and David Kennedy, "Multiphase CFD modelling and PIV validation of a UASB reactor", AIP Conference Proceedings 2116, 030007 (2019), DOI: 10.1063/1.5113991}

This Conference Paper is brought to you for free and open access by the School of Mechanical and Design Engineering at ARROW@TU Dublin. It has been accepted for inclusion in Conference Papers by an authorized administrator of ARROW@TU Dublin. For more information, please contact arrow.admin@tudublin.ie, aisling.coyne@tudublin.ie,gerard.connolly@tudublin.ie. Funder: PETROBRAS; TU Dublin

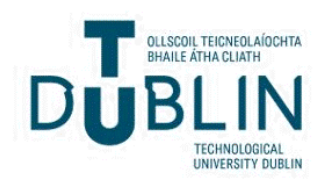




\section{Authors}

Camila D' Bastiani, Jéferson Luis Alba, Gabriel Tomazzoni Mazzarotto, Severino Rodrigues de Farias Neto, Lademir Luiz Beal, Anthony Reynolds, and David Kennedy 
See discussions, stats, and author profiles for this publication at: https://www.researchgate.net/publication/334686330

\section{Multiphase CFD modelling and PIV validation of a UASB reactor}

Conference Paper in AIP Conference Proceedings · July 2019

DOI: $10.1063 / 1.5113991$

CITATIONS

7 authors, including:

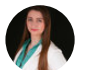

Camila Bastiani

Technological University Dublin - City Campus

3 PUBLICATIONS 7 CITATIONS

SEE PROFILE

Lademir Luiz Beal

Universidade de Caxias do Sul (UCS)

36 PUBLICATIONS 223 CITATIONS

SEE PROFILE

Some of the authors of this publication are also working on these related projects:

Project Investigação da distribuição de cimentos em vértebras injetados a partir de parafuso pedicular: modelagem e simulação View project

Environmental Sustainability and Health Institute View project

\section{READS}

234

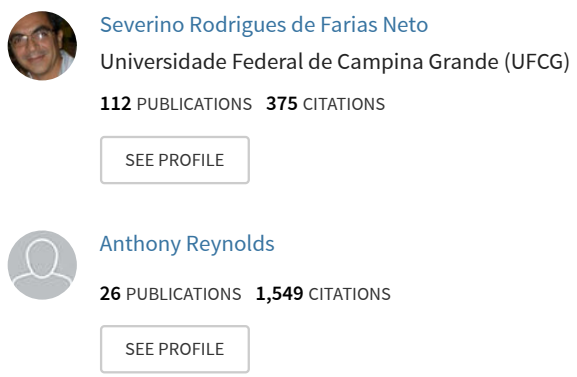




\section{Multiphase CFD modelling and PIV validation of a UASB reactor}

Cite as: AIP Conference Proceedings 2116, 030007 (2019); https://doi.org/10.1063/1.5113991

Published Online: 24 July 2019

Camila D'Bastiani, Jéferson Luis Alba, Gabriel Tomazzoni Mazzarotto, Severino Rodrigues de Farias Neto, Lademir Luiz Beal, Anthony Reynolds, and David Kennedy

\section{Conference Proceedings}

Get $30 \%$ off all print proceedings!

\section{Enter Promotion Code PDF-30 at checkout}

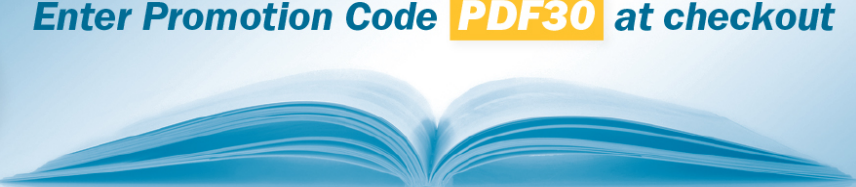




\title{
Multiphase CFD Modelling and PIV Validation of a UASB Reactor
}

\author{
Camila D’ Bastiani ${ }^{1, \text { a) }}$, Jéferson Luis Alba², Gabriel Tomazzoni Mazzarotto ${ }^{2}$, \\ Severino Rodrigues de Farias Neto ${ }^{3}$, Lademir Luiz Beal ${ }^{2}$, Anthony Reynolds ${ }^{1}$, \\ David Kennedy ${ }^{1}$
}

\author{
${ }^{1}$ School of Mechanical Engineering, Dublin Institute of Technology (DIT), 1 Bolton St, Rotunda, Dublin, Ireland. \\ ${ }^{2}$ Environmental Technology Laboratory (LATAM), University of Caxias do Sul (UCS), 1130, Francisco Getúlio \\ Vargas St, Caxias do Sul, RS, Brasil. \\ ${ }^{3}$ Department of Chemical Engineering, Centre for Science and Technology, Federal University of Campina Grande \\ (UFCG), 882, Aprígio Veloso St., Campina Grande, PB, Brasil. \\ a)camila.dbastiani@dit.ie
}

\begin{abstract}
Upflow anaerobic sludge blanket (UASB) reactors stand out as a feasible option for treating wastewaters while generating a valuable amount of biogas. It is known that the efficiency of UASB reactors is closely linked to its hydrodynamics. Therefore, understanding the role of each phase (solids, liquid and gas) in the mixing conditions inside the reactor and having validated numerical models for predicting the flow behavior has become fundamental for the design and optimization of UASB reactors. In this context this work aims to develop and validate a three phase Computational Fluid Dynamics (CFD) model of an UASB reactor. Eulerian-Eulerian laminar three-dimensional multiphase simulations were carried out using Fluent 16.2. The model was validated using Particle Image Velocimetry (PIV) experiments. The reactor was divided into four regions, according to its mixing conditions. Validation results showed differences between experimental and computational results for the liquid velocity to be less than $4 \%$. Dead zones accounted for $0.02 \%$ of the total volume of the reactor. From the simulation results, a sludge wash out of $179 \mathrm{mg} \cdot \mathrm{L}^{-1}$ was found. The validated model can be further used for optimization studies for this type of wastewater treatment bioreactor.
\end{abstract}

\section{INTRODUCTION}

Upflow anaerobic sludge blanket (UASB) reactors stand out as a feasible option for treating a wide range of industrial and domestic wastewater ${ }^{1-3}$. Due to its concept, the anaerobic processes in UASB reactors are closely linked to its hydrodynamics, which plays a major role in improving the treatment performance ${ }^{4}$. Therefore, fully understanding the hydrodynamics in this kind of reactor can lead to improvements on the treatment efficiency and thus on the biogas yield. In UASB reactors, the wastewater (liquid) moves upwards through a granular sludge bed (solid). Due to the anaerobic reactions, the organic matter is converted into biogas (gas). Small bubbles of gas are formed and coalesce in order to be able to move up to the end of the sludge bed, where they are then released and move up to the top of the reactor, where the biogas is collected. Considering the complex multiphase nature of the flow in UASB reactors, Computational Fluid Dynamics (CFD) arises as a powerful tool to optimize the reactor performance. As cited by Samstag et al. ${ }^{5}$, in recent years CFD has become widely used for analysis of wastewater treatment problems, especially concerning hydraulic behavior. Meeting that need, this work aims to develop a three phase model using CFD and to validate it using particle image velocimetry (PIV) experiments, thus advancing the state-of-the-art on the modelling of wastewater treatment UASB bioreactors. The validated model can be used for further optimizations of this type of bioreactor. 


\section{METHODOLOGY}

This study comprised two stages. For the first stage a numerical model was developed, accounting for the interactions between the three phases (solid, liquid and gas). The second stage consisted of an experimental set up of PIV experiments to account for the liquid phase velocities.

\section{Numerical Model}

Throughout this work, 3-D transient laminar isothermal simulations were carried out using the Eulerian-Eulerian (E-E) approach to predict the flow field in a UASB reactor. Two dispersed (solid and gas) and one continuous phase (liquid) were assumed. Heat and mass transfer between the phases was neglected. Thus, the mass and momentum conservation of the phases were governed solely by the following momentum conservation equation:

$$
\begin{gathered}
\frac{\partial}{\partial t}\left(\alpha_{q} \rho_{q} \vec{v}_{q}\right)+\nabla \cdot\left(\alpha_{q} \rho_{q} \vec{v}_{q} \vec{v}_{q}\right)-\alpha_{q} \nabla P+\nabla \cdot \overline{\bar{\tau}}_{q}+\alpha_{q} \rho_{q} \vec{g}+\sum_{p=1}^{n}\left(K_{p q}\left(\vec{v}_{p}-\vec{v}_{q}\right)+\left(\vec{F}_{b}+\vec{F}_{I n t}\right)\right. \\
\vec{F}_{I n t}=\vec{F}_{D}
\end{gathered}
$$

where $\mathrm{q}$ stands for the continuous phase and, $\mathrm{p}$ for the dispersed phases; $\alpha$ is the volumetric fraction; $\rho$ is the density of the phase; $\vec{v}$ is the phase velocity; $\vec{g}$ is the gravity acceleration; $P$ the pressure; $\overline{\bar{\tau}}_{q}$ the phase stress tensor; $K_{p q}$ the interfacial exchange coefficient; $\vec{F}_{b}$ an external body force; $\vec{F}_{i n t}$ the interfacial forces term and $\vec{F}_{D}$ the drag force ${ }^{6}$.

In UASB reactors, the solid phase is formed by the anaerobic granules. In this work, the physical characteristics of the material used in the PIV validation were assumed for the solid phase. Thus, spheres with $2 \mathrm{~mm}$ of diameter and density of $1,050 \mathrm{~kg} \cdot \mathrm{m}^{-3}$ were simulated as the solid phase. The gas characteristics were calculated through the weighted average of the $\mathrm{CO}_{2}$ and $\mathrm{CH}_{4}$ properties (the main components of biogas). Thus, a density of $0.8578 \mathrm{~kg} \cdot \mathrm{m}^{-3}$, a dynamic viscosity of $1.1984 \times 10^{-5} \mathrm{~kg} \cdot(\mathrm{m} \cdot \mathrm{s})^{-1}$ and a bubble size of $2 \mathrm{~mm}$ were assumed. Town water with a density of 998.2 $\mathrm{kg} \cdot \mathrm{m}^{-3}$ and a dynamic viscosity of $0.001003 \mathrm{~kg} \cdot(\mathrm{m} \cdot \mathrm{s})^{-1}$ was used as the continuous phase in the numeric model.

Regarding the interfacial forces, authors had concluded that the drag force is the main force responsible for the interfacial momentum exchange in multiphase flows ${ }^{7-10}$. In order to determine the drag coefficient between solid (s) and liquid (l) $\left(C_{D, s l}\right)$, the model proposed by Gidaspow et al. ${ }^{11}$ was used (Eq. 3). The Schiller and Naumann ${ }^{12}$ model was chosen to determine the drag coefficient between the gas and liquid $\left(C_{D, g l}\right)$ phases as well as between the gas $(\mathrm{g})$ and solid $\left(C_{D, g s}\right)$ according to Eq. 4.

$$
\begin{gathered}
C_{D, s l}=\frac{24}{\alpha_{l} R e_{p}}\left[1+0,15\left(\alpha_{l} R e_{p}\right)^{0,687}\right] ; \text { where: } R e_{p}=\frac{\rho_{l} d_{S}\left|\vec{v}_{S}-\vec{v}_{l}\right|}{\mu_{l}} \\
C_{D, g l}=\left\{\begin{array}{cc}
24\left(\frac{1+0.15 R e^{0.687}}{R e}\right) & R e \leq 1000, \\
0.44 & R e>1000,
\end{array} ; \text { where: } R e=\frac{d_{b}\left|v_{g}-v_{l}\right| \rho_{l}}{\mu_{l}}\right.
\end{gathered}
$$

where $\alpha_{l}$ is the liquid volumetric fraction; $d$ is the diameter either of the solid (s) or bubble (b); $\mu_{l}$ is the dynamic viscosity of the liquid.

For the solid phase modeling, the Kinetic Theory of Granular Flow (KTGF) was used. The three phases were considered at $293.15 \mathrm{~K}$ and $1 \mathrm{~atm}$. At the liquid inlet a velocity of $0.00711 \mathrm{~m} \cdot \mathrm{s}^{-1}$ was assumed and at the gas inlet a velocity of $0.00112 \mathrm{~m} \cdot \mathrm{s}^{-1}$. For both cases a reference operating pressure of $101,325 \mathrm{~Pa}$ was used, once the outlet pressure was considered zero, so the absolute pressure would correspond to the atmospheric pressure at the outlet boundary condition.

Monitors were created in order to assess the convergence, and the residuals were also monitored. Unsteady results for $135 \mathrm{~s}$ were collected, between $100 \mathrm{~s}$ and $235 \mathrm{~s}$. Regarding the mesh, previous mesh independence studies were carried out, using the Grid Convergence Index (GCI) method, proposed by Roache ${ }^{13}$. Thus, a mesh with 528,000 elements was chosen.

\section{Experimental Setup}

To experimentally simulate the flow in a UASB reactor, a small scale UASB was used. The reactor was built in poly (methyl) methacrylate (PMMA) in order to allow the internal flow visualization. It was built with $2.12 \mathrm{~m}$ height and $0.3 \mathrm{~m}$ diameter. A usable volume of $140 \mathrm{~L}$ was assumed.

The CFD model was validated using a PIV system to collect data about the flow inside a small scale UASB reactor. The PIV technique is known as a non-intrusive method, used to analyze characteristics of a flow. It is known as one of the major tools to measure velocity fields in experiments ${ }^{14}$. It consists in adding tracer particles into the flow, 
assuming that its behavior will mimic the flow profile. Later, two laser pulses were fired with a short time gap between them and CCD cameras were used to capture the displacement of the particle between the laser pulses. A computer, using DaVis 8.8.2 software, was then used to process and analyze the images acquired by the cameras. The software calculates the particle displacement between the two laser pulses and correlates the two cameras frames in order to produce an instantaneous vector field of the flow. The results reported by the processing of the images showed information about the flow observed. For this work, a stereoscopic PIV (LaVision) was used. The tracers consisted of fluorescent $20-50 \mu \mathrm{m}$ tracer particles. The laser head was positioned in order to illuminate the central longitudinal plane of the UASB reactor and the cameras were placed at angles of $60^{\circ}$ and $120^{\circ}$ in relation to this plane.

\section{RESULTS}

Two PIV experiments were performed and the averaged results were used for the CFD model validation. Due to experimental limitations, the PIV results for a plane located at the center of the reactor (longitudinal section), with dimensions of $1.0 \mathrm{~m}$ height and with $0.2 \mathrm{~m}$ of diameter, were compared with CFD results. Table 1 shows the validation results for two parameters: water upflow velocity and water velocity magnitude.

TABLE 1. Comparison of Results.

\begin{tabular}{lccc}
\hline & PIV & CFD & Difference $(\%)$ \\
\hline Water Upflow Velocity $\left(\mathrm{m} \cdot \mathrm{s}^{-1}\right)$ & -0.0154 & -0.0157 & -1.95 \\
Water Velocity Magnitude $\left(\mathrm{m} \cdot \mathrm{s}^{-1}\right)$ & 0.0186 & 0.0180 & 3.23 \\
\hline
\end{tabular}

The differences between experimental and computational results were less than $4 \%$. Thus, the validation results were considered satisfactory, given the complexity of the flow system, allowing the following analysis on the overall UASB hydrodynamics behavior.

According to Ren et al. ${ }^{15}$ there is a discontinuity in the mixing behavior along the height of UASB reactors. This discontinuity was also noticed in the simulations performed in this study and, therefore, the reactor could be divided into four hydraulic regions: bottom, transition, upper and top (Fig. 1). The absence of sludge or the presence of a very small volume fraction on the upper and top regions (Fig. 2) are in accordance with the results obtained by Ren et al. 15 for a similar UASB reactor. Moreover, it was observed that the gas injected into the reactor drove liquid recirculation along the axial position, improving the mixing conditions within the reactor.

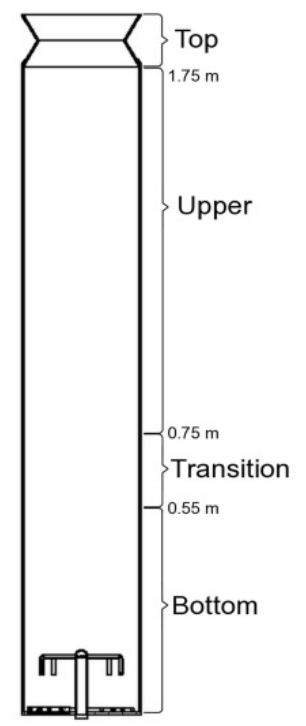

FIGURE 1. Four regions of the small scale reactor according to its hydrodynamics conditions.

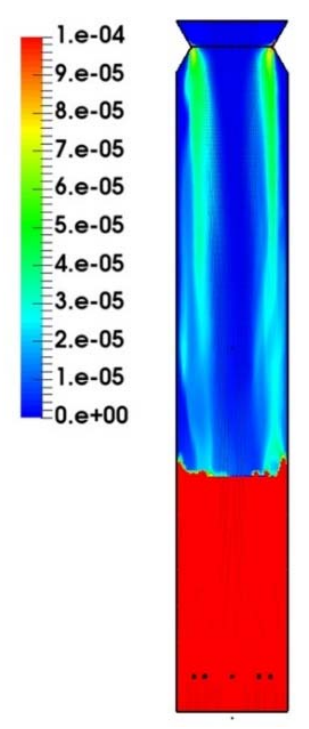

FIGURE 2. Sludge volumetric fraction at a plane in the center of the reactor.

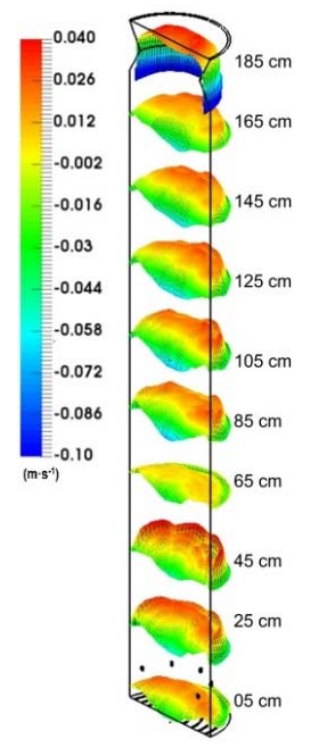

FIGURE 3. Liquid upflow mean velocity profiles at the heights: $5 \mathrm{~cm} ; 25 \mathrm{~cm} ; 45 \mathrm{~cm} ; 65 \mathrm{~cm} ; 85 \mathrm{~cm}$; $105 \mathrm{~cm} ; 125 \mathrm{~cm} ; 145 ; 165 \mathrm{~cm} ; 185 \mathrm{~cm}$. 
Figure 3 shows the profiles for the upflow mean velocity at different heights along the reactor. It is possible to observe that the lower velocities are located at the center of the reactor and close to the walls, indicating the liquid recirculation streams. Regarding the mixing, Ren et al. ${ }^{15}$ define the dead zones as the regions where the superficial liquid velocities are less than $5 \%$ of the average velocity. Using CFD simulations of a UASB reactor, the authors found that $10 \%$ of the reactor volume could be considered as dead zones. Singh et al. ${ }^{16}$ determined the dead zones for an $8 \mathrm{~L}$ experimental reactor, operating at $32^{\circ} \mathrm{C}$ and at $20^{\circ} \mathrm{C}$. Results for the different temperatures showed, respectively, $10 \%$ and $11 \%$ of the volume as stagnant zones. In the present work, only $0.02 \%$ of the volume could be considered as dead zones, a value far below the ones found in the literature.

Ruttithiwapanich et al. ${ }^{17}$ investigated the cause of sludge wash-out in a UASB reactor. The authors mention that sludge wash-out within the reactor originates from the liquid velocity overcoming the solids terminal velocity. They also say that loss of sludge through the system outlet is a negative effect in UASB reactors. In the present work, the mean liquid upflow velocity of $6.79 \times 10^{-5} \mathrm{~m} \cdot \mathrm{s}^{-1}$ did not overcome the solids mean terminal velocity of $-8.65 \times 10^{-3}$ $\mathrm{m} \cdot \mathrm{s}^{-1}$. Therefore, it was found a sludge wash-out of only $1.13 \times 10^{-3} \mathrm{~kg} \cdot \mathrm{h}^{-1}$ of solids from the reactor. Considering the

average liquid flow rate of $6.42 \mathrm{~L} \cdot \mathrm{h}^{-1}$ used in the design of the reactor, it was calculated that a solids concentration of $179 \mathrm{mg} \cdot \mathrm{L}^{-1}$ was carried out from the reactor, according to the simulation results.

\section{CONCLUSIONS}

The main conclusions that can be drawn from this study are: the configuration of the gas distribution system played a major role on the overall flow profile within the reactor at the lower regions, however, its influence was reduced at the upper and top regions; the gas injected into the reactor drove liquid recirculation along the axial position; at low liquid superficial velocities, biogas production plays a major role in the flow patterns in UASB reactors, which is why they are considered auto mixed reactors. Finally, considering that the validation results were satisfactory, the proposed model can be used in other simulations for UASB reactors optimization.

\section{ACKNOWLEDGMENTS}

The authors would like to acknowledge the financial assistance provided by PETROBRAS and by the Dublin Institute of Technology (DIT) through the Fiosraigh scheme.

\section{REFERENCES}

1 G. Lettinga and L. Hulshoff Pol, Water Sci. Technol. 24, 87 (1991).

2 K. Yetilmezsoy and Z. Sapci-Zengin, Stoch. Environ. Res. Risk Assess. 23, 13 (2009).

3 P. Dessì, R. Jain, S. Singh, M. Seder-Colomina, E.D. van Hullebusch, E.R. Rene, S.Z. Ahammad, A. Carucci, and P.N.L. Lens, Water Res. 94, 146 (2016).

4 J. Jiang, J. Wu, J. Zhang, S. Poncin, and H.Z. Li, Bioresour. Technol. 155, 1 (2014).

5 R.W. Samstag, J.J. Ducoste, A. Griborio, I. Nopens, D.J. Batstone, J.D. Wicks, S. Saunders, E.A. Wicklein, G. Kenny, and J. Laurent, Water Sci. Technol. 74, 549 (2016).

6 ANSYS, Theory Guide - Fluent 16.2 (2015).

7 J.M. van Baten, J. Ellenberger, and R. Krishna, Chem. Eng. Process. Process Intensif. 42, 733 (2003).

8 P. Chen, J. Sanyal, and M.P. Duduković, Chem. Eng. Sci. 60, 1085 (2005).

9 Y. Cheng and J.-X.J. Zhu, Can. J. Chem. Eng. 83, 177 (2005).

10 M.G.S. Lima, S.R. de Farias Neto, A.G.B. de Lima, F.C. Brito Nunes, and L.D.A. Gomes, Int. J. Chem. React. Eng. 9, 1 (2011).

11 D. Gidaspow, R. Bezburuah, and J. Ding, in VII Eng. Found. Conf. Fluid. (Engineering Foundation, New York, 1992).

12 L. Schiller and Z. Naumann, Zeitschrift Des Vereins Dtsch. Ingenieure 77, 318 (1933).

13 P.J. Roache, J. Fluids Eng. 116, 405 (1994).

14 M. Lemke, J. Reiss, and J. Sesterhenn, AIP Conf. Proc. 1738, 030017/1 (2016).

15 T.-T. Ren, Y. Mu, B.-J. Ni, and H.-Q. Yu, AIChE J. 55, 516 (2009).

16 K.S. Singh, T. Viraraghavan, and D. Bhattacharyya, J. Environ. Eng. 132, 895 (2006).

17 T. Ruttithiwapanich, W. Songkasiri, and W. Ruenglertpanyakul, IERI Procedia 5, 245 (2013). 